\title{
AVALIAÇÃO DA EDUCAÇÃO SUPERIOR NO BRASIL: PROCESSO DE CONSTRUÇÃO HISTÓRICA
}

\author{
Maria Amelia SabBag ZainKo* \\ * Professora/Pesquisadora do PPGE/UFPR. E-mail: maszainko@gmail.com \\ Resumo: O presente artigo analisa a construção do processo de avaliação da educação superior no Brasil \\ enfocando as diferentes concepções e suas implicações nas políticas atuais de avaliação. As mu- \\ danças atuais põem em risco os fundamentos do SINAES e não auxiliam no avanço das políticas \\ públicas para a educação superior.
}

Palavras-chave: Avaliação da educação superior. Concepções de avaliação. Políticas públicas.

EVALUATION OF HIGHER EDUCATION IN BRAZIL: HISTORICAL BUILDING PROCESS

\begin{abstract}
This article examines the construction of the process of higher education evaluation in Brazil focusing on the different concepts and their implications for the evaluation of current policies. The current changes put at risk the foundations of SINAES and do not aid the development of higher education public policies.
\end{abstract}

Key words: Evaluation of higher education. Concepts of evaluation. Public policies.

O processo de construção histórica da avaliação da educação superior no Brasil é marcado por avanços e retrocessos.

Como a educação de nível superior consiste em algo relativamente recente na história do Brasil, se comparada com a tradição milenar das universidades européias, a avaliação deste nível de educação também o é.

A proposta de avaliação em caráter mais sistematizado remonta ao início da década de sessenta quando o governo militar que vigorou no País de 1964 a 1985 a título de modernização submete a educação a um modelo "produtivista" de eficiência, como se as instituições educacionais fossem organizações semelhantes a empresas privadas.

O Grupo de Trabalho que propôs a Reforma Universitária de 1968 procede a um amplo diagnóstico e detecta a necessidade de incrementar o número de matrículas na Educação Superior acompanhando a tendência vigente em outros países de um fenômeno chamado de massificação.

Tem início aí o "boom" da expansão da Educação Superior com aumento indiscriminado de instituições e de matrículas, sem que com isso fosse assegurada a democratização do acesso com garantia de permanência e qualidade. 
Na década de 1980, com o esgotamento do modelo militar e já caminhando para a redemocratização do País, a avaliação da educação superior ganha destaque e é concebida como instrumento para a implementação de políticas que permitam a superação da crise que vive a universidade. O Programa de Avaliação da Reforma Universitária (PARU), de 1983, é produzido a partir de levantamento de dados e apreciação crítica da realidade da educação superior nacional, mediados por estudos, discussões e pesquisas, com a finalidade de realizar uma avaliação comparativa de todo o sistema.

Com a sua desativação em 1984 e com o entendimento de que a avaliação é instrumento essencial no controle da educação superior, é criada em 1985 a Comissão Nacional de Reformulação da Educação Superior, conhecida como a Comissão de Notáveis que, a partir de consultas à sociedade e, em particular, à comunidade universitária, deve propor soluções urgentes aos problemas da educação superior.

A comissão apresenta o relatório Uma Nova Política para a Educação Superior, no qual destaca como um dos mais graves problemas do ensino superior brasileiro a falta de parâmetros para que o governo tenha uma política racional de alocação de recursos públicos, que fortaleça as melhores instituições e induza as demais ao aperfeiçoamento. Indica ainda que a avaliação do ensino superior seja realizada a partir das seguintes dimensões: avaliação dos cursos, avaliação dos alunos; avaliação dos professores; avaliação didáticopedagógica do ensino; avaliação de servidores técnicos e administrativos; e avaliação das carreiras.

O documento por ela produzido não vai ao encontro das expectativas do Estado quanto à forma de controle da educação superior e é reformulado, ou melhor, significativamente modificado pelo Grupo Executivo para a Reforma da Educação Superior (GERES).

$\mathrm{Na}$ concepção do GERES, os representantes dos órgãos governamentais - embora possam contar com a colaboração da comunidade acadêmica - constituem-se como os principais atores do processo avaliativo e a proposta de avaliação fundamenta-se em uma concepção regulatória da educação superior, dando enfoque às dimensões individuais (do alunado, dos cursos e das instituições).

A avaliação de desempenho cumpre papel importante tanto do ponto de vista do controle social da utilização de recursos, como também no processo de formulação de políticas e de estabelecimento de normas para o sistema educacional. 
A alocação de recursos públicos deve se dar em função do desempenho e devem ser direcionados, prioritariamente, às instituições com padrões internacionais de pesquisa e produção acadêmica os "Centros de Excelência".

O GERES é combatido de forma muito intensa pelo movimento docente que, por meio de sua associação - ANDES -, lança a proposta de um padrão unitário de qualidade para a universidade brasileira.

Assiste-se nos primeiros anos da década de 1990 no Brasil a existência de modelos avaliativos em conflito que defendem pressupostos diversos de educação superior, pautados em diferentes concepções de avaliação.

No governo Fernando Collor de Mello a concepção de avaliação da educação superior, articulada às demandas da reforma do Estado, pauta-se em uma ação centralizadora, autoritária e controladora por parte do Estado em relação às instituições de educação superior. A intenção de incrementar a eficiência e a produtividade das instituições de educação superior preocupa o meio acadêmico.

São instituídas as Comissões de Especialistas de Ensino com a incumbência de prestar assessoria à SESu na instalação de um processo permanente de avaliação, acompanhamento e melhoria dos padrões de qualidade do ensino superior.

Com o impeachment de Collor e já no Governo Itamar Franco, atendendo a uma demanda da comunidade acadêmica, pela Portaria $\mathrm{n}^{\circ} 130$, de 14 de julho de 1993, o Secretário da Educação Superior do MEC cria a Comissão Nacional de Avaliação com o objetivo de estabelecer diretrizes e viabilizar a implementação do processo de avaliação institucional nas universidades brasileiras. È criado o PAIUB, primeiro programa de avaliação institucional da Universidade Brasileira.

Neste modelo avaliativo, cabe ao MEC articular, viabilizar e financiar a avaliação da educação superior, estimulando a adesão voluntária das instituições a esta prática avaliativa. A avaliação é compreendida enquanto um processo de acompanhamento metódico das ações realizadas pela instituição de educação superior, com vistas a averiguar em que medida são cumpridas e atendidas as funções e prioridades delimitadas coletivamente.

Com a titularidade da avaliação nas mãos da comunidade acadêmica e a educação entendida como um bem público, o PAIUB aposta na construção de práticas avaliativas que sejam participativas, contínuas e sistemáticas, afinadas com o debate público e com a função social da educação superior no momento histórico. 
Com a mudança de Governo e a assunção de Fernando Henrique Cardoso, em 1995, o modelo avaliativo do PAIUB não se mostra adequado enquanto alicerce para dar os subsídios necessários ao MEC para o desempenho das funções de coordenação e controle do sistema de educação superior.

É demandada uma prática avaliativa que apresente mais afinidade com os pressupostos de redução do papel do Estado no provimento de ensino superior, que lhe possibilite, contudo, manter o controle último do sistema. Interessa a constituição de um sistema avaliativo que tenha como um de seus pilares a averiguação dos produtos educacionais, em especial daqueles relacionados ao ensino, que possibilite constatar quais conhecimentos (e em que medida) são adquiridos pelos alunos ao longo do ensino superior e que possa ser organizado de forma que permita a comparabilidade entre as performances das diferentes instituições.

Pela Lei 9.131/95 é estabelecido o Exame Nacional de Cursos, que ficou popularmente conhecido como Provão e que fruto de uma bem articulada campanha de marketing caiu no gosto da população.

Os procedimentos adotados para as avaliações incluíam, necessariamente, a realização, a cada ano, de exames nacionais com base nos conteúdos mínimos estabelecidos para cada curso, previamente divulgados e destinados a aferir os conhecimentos e competências adquiridos pelos alunos em fase de conclusão dos cursos de graduação.

Com o término do mandato de FHC e a partir da posse de Luiz Inácio Lula da Silva na Presidência da República, em 2003, ocorre uma série de mudanças nas políticas de educação superior, dentre as quais constam as políticas de avaliação. O Sistema Nacional de Avaliação da Educação Superior (SINAES) implementado pelo governo encerra uma série de possibilidades se comparado à sistemática adotada pelo governo anterior.

O SINAES tem por finalidade a melhoria da qualidade da educação superior, a orientação da expansão da sua oferta, o aumento permanente da sua eficácia institucional e efetividade acadêmica e social, e especialmente a promoção do aprofundamento dos compromissos e responsabilidades sociais das instituições de educação superior, por meio da valorização de sua missão pública, da promoção dos valores democráticos, do respeito à diferença e à diversidade, da afirmação da autonomia e da identidade institucional. (PORTARIA MEC n. $2.051 / 04$, art. $1^{\circ}$ ).

Com ele o MEC pretende proporcionar a articulação da ação de regulação estatal da educação superior com a dimensão de emancipação das IES e da 
prática educativa realizada por estas - levando-se em consideração, evidentemente, os limites e possibilidades históricas para tanto.

Os membros da comunidade acadêmica constituem-se como sujeitos da prática avaliativa - que engloba a avaliação das IES, dos cursos de graduação e do desempenho acadêmico - afinal esta se configura enquanto condição "sine qua non" para a realização de uma "análise global e integrada do conjunto das dimensões, estruturas, relações, compromisso social, atividades, finalidades e responsabilidades sociais da instituição de educação superior". (PORTARIA MEC $n^{\circ} 2.051 / 04$, art. $8^{\circ}$ )

Buscando consolidar uma cultura de avaliação institucional na qual fique evidente a mudança de concepção de avaliação que supera a sua fase estática característica do Provão, passando para uma forma de avaliação processual e dinâmica, o SINAES encerra o seu primeiro ciclo de três anos com vícios que estiveram presentes na sua origem.

Os problemas mais evidentes e que demandam providências são: a fragilidade da "cultura de avaliação", a insuficiência de pessoal capacitado para dar conta da avaliação em nova concepção, as dificuldades da composição política da CONAES, a insuficiência de pessoal técnico para a análise dos relatórios de auto-avaliação.

Nas IES a constituição da Comissão Própria de Avaliação - CPA esbarra em problemas políticos e na escassez de pessoal familiarizado com a questão, na insuficiência de discussões internas e nas dificuldades para a realização da auto-avaliação.

No MEC, o principal problema é a concepção de que a avaliação deve ser sustentada por índices de desenvolvimento pautados por indicadores quantitativos que permitam a elaboração de "ranking". O que se vê com o IDEB (Índice de Desenvolvimento da Educação Básica) é o que se viu no nascedouro do SINAES, ainda em 2003, na tentativa de transformá-lo em IDES (Índice de Desenvolvimento da Educação Superior).

Atualmente em nome do SINAES e ao mesmo tempo sepultando seus principais fundamentos vêm aí as novidades: conceito preliminar de cursos - CPC, Indicador de desempenho esperado e observado - IDD e índice geral dos cursos - ICG. 